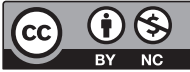

\title{
Temporalidade e propriedade em Ser e Tempo de Heidegger
}

\section{Temporality and property in Heidegger's Being and Time}

\section{Cezar Luís Seibt}

Docente da Universidade Federal do Para (UFPA), Cametá, PA - Brasil, e-mail: celuse@ufpa.br

\section{Resumo}

Em Ser e Tempo, Martin Heidegger pretende mostrar e superar a objetificação realizada pela Metafísica retomando a questão do sentido do ser. Tal superação passa pela desconstrução do conceito de tempo, marca fundamental da compreensão tradicional da realidade e, inclusive, da compreensão do que seja o próprio ser humano. No lugar do tempo da ontologia da coisa, linear, sugere ele a temporalidade enquanto sentido do ser do Dasein. Este texto busca acompanhar o autor nesta diferenciação e mostrar a nova compreensão de ser humano que dela surge. Do tempo da coisa para o tempo do Dasein, da impropriedade para a propriedade.

Palavras-chave: Tempo. Temporalidade. Propriedade. Analítica existencial. Metafísica. 


\begin{abstract}
In Being and Time Martin Heidegger wants to show and overcome the Metaphysical objectification considering the question of sense of being. This overrun goes through the deconstruction of the concept of time, fundamental mark of the traditional understanding of reality and including the understanding of what the human being is. In place of the time of things ontology, linear, he suggests a sense of temporality as sense of being of Dasein. This text try to accompany the author in this differentiation and show the new understanding of human being that appears. From time of thing to the time of Dasein, from impropriety to property.
\end{abstract}

Keywords: Time. Temporality. Property. Existential analytic. Metaphysic.

\title{
Considerações introdutórias
}

O fio condutor do pensamento de Heidegger, sua meta, é a elaboração da questão do sentido do ser. Como a questão do ser só surge e repercute num ente determinado, que compreende e está disposto afetivamente, o ponto de partida deverá ser o esclarecimento deste ente, chamado Dasein. Heidegger acredita que, tornando mais originariamente acessível o ser deste ente, obtémse um horizonte seguro, um fundamento para a investigação do sentido do ser em geral, uma ontologia fundamental. Para isso a analítica do Dasein em Ser e Tempo é um caminho, um esforço neste sentido. Se esse caminho é correto ou até mesmo o único, somente é possível dizer depois que ele tiver sido percorrido.

Tendo retornado à constituição originária do ser do Dasein, Heidegger (1998, § 83) se pergunta se esse caminho levou ou não ao que se pretendia. Tendo chegado à temporalidade, há algum caminho que leve dela até o sentido do ser em geral? O tempo originário se revela realmente como horizonte do ser? Ou seja, tendo procurado superar a visão de tempo tradicional em direção à temporalidade originária do ser humano, é possível agora repensar o ser para além da objetificação e presentificação tradicionais?

Sabemos que Heidegger não completa a obra segundo o seu projeto inicial, alegando, sobretudo, uma insuficiência nos recursos da linguagem. Além do mais, Heidegger realiza nas obras posteriores uma mudança na perspectiva 
por meio da qual persegue o seu problema, no sentido de buscar o sentido do ser a partir do próprio ser e não mais pelo esclarecimento do Dasein. Mas isso não invalida a analítica existencial; ao contrário, essa se mantém ainda necessária no caminho.

Não há dúvidas, apesar das controvérsias sobre seu envolvimento político, que Heidegger é um autor cuja obra tem provocado um profundo impacto nas pesquisas e compreensões atuais em diversos âmbitos do conhecimento. O seu empenho tem sido uma luta com conceitos, com entendimentos que pressionam os estreitos limites de um pensamento que se move nas a a partir das possibilidades oferecidas pelo cotidiano e, sobretudo, por um modelo objetivista. Empenha-se por reconquistar o Dasein para si mesmo, reaver o ser humano na sua propriedade e originariedade. Cotidianamente o ser humano está capturado pelas coisas que realiza, pela familiaridade com um determinado âmbito de abertura no mundo. Mas o próprio mundo está oculto. Encontram-se coisas no mundo, acontecimentos, mas o mundo, ele mesmo, permanece oculto naquilo que se manifesta nele. Como mostra Grondin (2007, p. 11), ao comentar que a compreensão do ser se realiza a partir do cuidado e da fuga do cuidado, a razão disso é "a tendência do Dasein de entender o ser 'sem o tempo', ou seja, como permanente presença”.

A questão é: como sair desse estado e conquistar novamente a si mesmo, evitar a fuga e encaminhar-se para a autenticidade? Por meio do estado que a angústia provoca, mostra Heidegger (1998, § 40), em Ser e Tempo. Ela revela novamente a finitude do Dasein, que é atestada no ser-paraa-morte, e também aponta para o próprio mundo, para a constituição originária do ser-no-mundo. Ela mostra que o Dasein enquanto mundo, desvelador de mundo, tem essa sua própria condição encoberta. $O$ fato de ser desvelador do mundo está velado. Com a morte, o fim das possibilidades, torna-se acessível a temporalidade própria. Pode-se escutar novamente a consciência que chama para si mesmo, para a propriedade, manifesta-se o ser culpado e aponta-se para a resolução. Há uma passagem a ser realizada: dos entes que se manifestam no mundo para o próprio mundo. Melhor dizendo, para a mundanidade do mundo. Essa passagem para o mundo é operada por meio da descrição do ocultamento cotidiano em direção à propriedade.

Como já dissemos, o problema fundamental que Heidegger tem em mente, e ele explicita isso com frequência, é a elaboração adequada da questão do sentido do ser. Mas em função de que esse é o problema de Heidegger e como ele chega ao Dasein por essa via? Em primeiro lugar, colocar o sentido do ser em questão é pretender repensar de outro modo o fundamento da nossa 
compreensão e do nosso ser, do âmbito em que nos movemos no mundo. Ser é o âmbito do aberto, do desoculto, mas é também a própria condição de possibilidade do desocultamento. Heidegger percebe que há algo como uma determinação, um condicionamento no modo e nas possibilidades do pensamento metafísico. É preciso remontar às suas origens, às condições que sustentam o próprio pensamento.

Dessa forma, Heidegger encaminha o problema no sentido de buscar essas origens e fundamentos a partir de um paciente e perspicaz trabalho de desconstrução do modo de ser do ente que pergunta pelo sentido do ser, que já sempre tem uma compreensão prévia do ser. Entre os entes há um único a partir do qual se pode falar que há algo como ser, que transcende, é clareira, que é e está na abertura, que forma mundo. Só o Dasein pode dizer que algo é, a partir dele instaura-se algum sentido, uma abertura.

Como tal, o Dasein já é sempre num mundo, é ser-no-mundo, é uma abertura finita e histórica. Com base neste fato, encurtam-se as possibilidades de fundamentação da compreensão, que deverá ser entendida a partir da abertura finita do mundo e não pelo recurso a alguma entidade ou dimensão exterior, eterna e a-histórica.

Como ser-no-mundo, o ser humano está ocupado com os entes, os descobriu e familiarizou-se com eles. Por meio da disposição afetiva, da compreensão e do discurso efetiva-se essa abertura do ser-no-mundo. No entanto, nesse lidar o Dasein está sempre primeiro e em geral disperso e perdido na impessoalidade do 'a gente' (Das Man) (1998, § 25 a 27). Tal condição fáctica não é entendida de forma negativa, mas como o modo finito e histórico no qual irremediavelmente se constitui a abertura. Nela o Dasein tem a tendência de interpretar a si mesmo a partir do mundo da impessoalidade, permanecer à mercê da tradição, privado do poder de dirigir a si mesmo, de perguntar e escolher. As possibilidades próprias lhe são subtraídas pela tradição. Como diz o próprio Heidegger (1998, p. 153),

[...] primeiro eu não 'sou' 'eu', no sentido do próprio si mesmo, senão que sou os outros a maneira do 'a gente' (Man). Desde este e como este estou dado imediatamente a mim mesmo. Imediatamente, o Dasein é o 'a gente', e regularmente se mantém nisso. Quando o Dasein descobre e aproxima para si o mundo, quando abre para si mesmo o seu próprio modo de ser, este descobrimento do 'mundo' e esta abertura do Dasein sempre se levam a cabo como um afastar de encobrimentos e obscurecimentos, e como uma quebra das dissimulações com as quais o Dasein se fecha frente a si mesmo.

Rev. Filos., Aurora, Curitiba, v. 22, n. 30, p. 247-266, jan./jun. 2010 
Na cotidianidade, portanto, o Dasein está decaído e encoberto para si mesmo na sua constituição essencial como ser-no-mundo. Nas ocupações e preocupações o Dasein se perde de si mesmo, decai e foge de si e nem percebe que cai e foge. Esse encobrimento é garantido no falatório, na curiosidade e na ambiguidade ( $\$ 25$ a 27). Mas quando ele se re-descobre como ser-no-mundo, encontra a si mesmo na sua originariedade. Isso significa que ele re-descobre o mundo, torna transparente para si mesmo o seu modo de ser e, com isso, liberta as possibilidades autênticas do conhecimento. Podemos dizer que ele desencobre o encobrimento que aconteceu do fato de ele mesmo ser a condição de qualquer sentido, de haver algo como mundo. É preciso mostrar que na cotidianidade mantém-se encoberto esse fato originário do Dasein ser esse des-encobridor, de ser a condição de possibilidade do mundo. Essa transparência libera a verdade, a liberdade, a finitude, a temporalidade e a historicidade do Dasein.

Mas por que há no Dasein essa tendência de decair, de instalar-se no seu mundo? Heidegger dirá que é porque quando ele toma consciência do fundo do qual ele emerge, ao procurar compreender-se pelas raízes, ele pode descobrir que aí não há nada, há um vazio. Percebe que não há apoio em lugar nenhum, que seu fundamento é precário, que não há fundamento como ponto de apoio objetivo. Descobre-se ele como a abertura finita do mundo. O único apoio é seu 'aí' $(D a)$.

Como fazer então para que a singularidade da vida humana possa se mostrar? Isso é possível, em Ser e Tempo, por meio da angústia, como já mostramos, que destrói a tranquilidade e normalidade das construções teóricas e práticas e desvela o fundamento finito da compreensão do homem com ser-aí, como existente. A coragem para a angústia é a coragem para experimentar a própria transparência, ou seja, faz o indivíduo isolado cair fora das relações de familiaridade com o mundo e o confronta com a nudez do mundo e de si mesmo, contra a tentativa de toda atividade cotidiana de fugir dessa disposição. A irrupção para o ser próprio se dá no encontro com a experiência da contingência: não há nada por trás, não há sentido objetivo. A propriedade resiste à tendência da fuga, está voltada para o nada, e isso significa vir ao mundo mais uma vez.

Realizada a descrição do modo de ser decaído na cotidianidade na primeira seção de Ser e Tempo, que Heidegger caracteriza como imprópria, na segunda a investigação será conduzida a partir da temporalidade, que deverá encaminhar a possibilidade do poder-ser próprio. O ser deverá ser compreendido a partir do horizonte da temporalidade, do tempo próprio. $\mathrm{O}$ encontro 
consigo, com os entes simplesmente dados ou disponíveis e com a tradição não se dá a partir de uma verdade eterna, a-temporal, mas exatamente enquanto modo de ser do ente que compreende e que tem seu ser implicado nesta compreensão. Tendo des-coberto o tempo, o Dasein volta para si mesmo e seu próprio pensar para, a partir do tempo compreendido, pensar a temporalidade do próprio pensar. O sentido do ser é o tempo (daí Ser e Tempo) e, portanto, não pode mais haver fuga para fora do tempo, para um ser absoluto, para o que é estável e eterno.

Esse horizonte aberto do tempo mostra que coisas incertas nos aguardam no futuro, mas uma, embora imprevisível, é certa: a morte (1998, $\S 46$ a 53). E a efetivação dessa possibilidade destrói qualquer outra possibilidade e, inclusive, a própria existência. Mas ela já está presente a cada momento, pois podemos vivenciar o 'passar' do tempo. O ser-para-o-fim está dentro da própria vida. E cada um tem de morrer a própria morte, ninguém pode ser substituído e nem substituir outrem nesse acontecimento. Por isso, a morte individualiza e mostra que não podemos repousar no tempo, ou consolar-nos com pensamentos de eternidade. O sentido do ser não é algo persistente, presente, mas acontecimento. E, ao descobrir-se autenticamente para a morte, o Dasein torna-se mais originariamente acessível para si mesmo. Precisa renunciar aos alívios providenciados pela cotidianidade e suportar a si mesmo, depender de si mesmo. Desligando-se do impessoal, o Dasein chega à consciência da mortalidade e do tempo, descobre a inconsistência de tudo que é providenciado pelo impessoal e público, e toma consciência do próprio poder-ser, da liberdade e transcendência que produz iniciativa, espontaneidade e criatividade.

Visto a partir da temporalidade, o Dasein não se restringe em sua consciência ao momento presente, mas se projeta no futuro e retrocede ao passado. Sendo adiante de si mesmo, antecipando a possibilidade da morte, ele liberta-se das amarras do 'a gente' (Das Man). Tendo consciência dessa possibilidade, ele vê sua situação e as possibilidades que essa lhe oferece, e toma uma decisão. A certeza da morte influi no modo como a vida é organizada, dá-lhe uma nova perspectiva.

Mas a partir de onde o Dasein pode escolher entre possibilidades diferentes daquelas concedidas pelo 'a gente', pelo impessoal? Heidegger dirá (1998, § 54 a 60) que é pelo chamado da Consciência. Ela é aquela que diz que ele tem de optar por escolher. Tal chamado vem do próprio Dasein, que nunca está total e irrecuperavelmente absorvido no 'a gente', e lhe revela o seu ser culpado. O Dasein, dessa forma, torna-se resoluto, ou seja, afasta-se da multidão e toma suas decisões à luz da sua vida como um todo. O Dasein

Rev. Filos., Aurora, Curitiba, v. 22, n. 30, p. 247-266, jan./jun. 2010 
resoluto vai antecipadamente ao encontro de sua morte e remonta ao seu passado antes de decidir o que fazer no presente ou instante. Assim, por meio da resolução (Entschlossenheit), o presente é retirado da dispersão da ocupação imediata, e é retido no futuro e no passado. O presente recolhido da dispersão por meio da resolução, que é um presente próprio, Heidegger chama de 'instante' (Augenblick).

Esse caminho todo mostrou que o ser-no-mundo do Dasein é cuidado e este está, em primeiro lugar, faticamente já sempre distraído e absorvido em e pelo seu mundo, pelos entes de que cuida, com que lida e está familiarizado. Mas essa não é a única possibilidade dele: ele tem uma potencialidade originária para perceber essa absorção e de voltar a si mesmo, e disso ele é capaz por meio da angústia. Nela ele ouve a voz do chamado da Consciência que o chama de volta às suas possibilidades próprias e lhe mostra o fato originário de ser sempre culpado, de ser pura possibilidade, nu e sem lar, e de ter sobre si a carga da sua existência, do seu próprio ser. Assim, o Dasein vive, como um todo, num ir-e-vir entre a distração e o recolhimento e isso é tudo o que há. Heidegger quer, com isso, mostrar o 'fundo do mundo', a mundanidade do mundo. O Dasein que se apropria de si mesmo, reconhece esse abismo que ele mesmo é enquanto ser-no-mundo, esse fundamento sem fundo e, como tal, encontra suas raízes e liberta-se enquanto ser de possibilidades.

Mas 'mundo', o que é isso? Em Heidegger, agora, mundo não é mais a simples totalidade dos entes que compõem o espaço em que cada ser humano se move. Não é, simplesmente, o mundo espacial. É o horizonte de sentido, a abertura do ser, a clareira na qual as coisas e os acontecimentos podem se mostrar, onde adquirem algum sentido. Mundo é a abertura onde o mundo comum (dos entes e do espaço) pode aparecer e fazer sentido.

Deter-nos-emos agora na análise da segunda seção de Ser e Tempo, na qual Heidegger avança fazendo uma releitura das conquistas da primeira seção (descrição da cotidianidade, do modo como normalmente o ser humano é no mundo), evidenciando novos elementos que superaram, a partir da temporalidade e não do tempo, da historicidade e não da história, as compreensões tradicionais do ser humano e do próprio ser.

\section{Temporalidade e abertura própria}

As estruturas que compõe a abertura, ou seja, a compreensão, a disposição afetiva, a decaída e o discurso, deverão ser o primeiro alvo da 
análise interpretativa do Dasein cotidiano agora orientada a partir da temporalidade. A interpretação realizada na primeira seção traz em sua base o sentido temporal do 'de início e na maior parte das vezes', uma possibilidade de temporalização que funda ontologicamente a impropriedade que, por sua vez, se apoia na presentificação, no sentido do tempo enquanto presente. $\mathrm{O}$ esclarecimento obtido não é suficiente, porque orientado por um sentido temporal impróprio, irresoluto. Para que se possa repensar o ser humano originariamente, é preciso partir não do tempo em sentido habitual, como simples sucessão de agoras, mas do tempo enquanto historicidade. Habitualmente se pensa a história como sucessão de fatos no tempo. Heidegger busca superar tanto a ideia do tempo como da história que herdamos da tradição, por serem pensadas a partir do presente, do ser humano enquanto presença. Pensar o ser humano originariamente implica passar da história para a historicidade e do tempo para a temporalidade. Nesta passagem ele se apropria de si mesmo, torna-se resoluto. Haar (1990, p. 61) diz que

o ser-resoluto não torna possível a temporalidade, mas a temporalidade, na sua estrutura 'espontânea', torna possível o resoluto. A temporalidade originária temporaliza, quer dizer, possibilita radicalmente todos os modos de ser do Dasein, confere sentido a todos os existenciais (a compreensão, a disposição afetiva e a decaída), mas sobretudo torna possível o autêntico e o inautêntico.

Os existenciais da compreensão, disposição afetiva, decaída e discurso, que compõem os momentos estruturais do cuidado e que Heidegger analisou inicialmente na primeira seção (intitulada de "Etapa preparatória da análise fundamental do Dasein") a partir da cotidianidade, deverão ser retomados e revisados sob essa nova ótica da temporalidade originária, o que ele realiza no parágrafo 68. Esses momentos se articulam assim: "Todo compreender tem um estado de ânimo. Toda disposição afetiva é compreensiva. O compreender afetivamente disposto tem o caráter da decaída. A compreensão decaída e animicamente afinada articula sua compreensão no discurso" (HEIDEGGER, 1998, p. 352-353).

\section{A temporalidade da compreensão}

É o compreender que, enquanto compreensão primária do Dasein, possibilita e funda os fenômenos derivados da explicação, teorização e todas 
as espécies de conhecimento e desconhecimento. Ele abre o poder-ser do Dasein no qual ele já sempre tem uma noção do que se passa consigo. Mas o poder-ser só é possível com base num futuro, que se torna condição de uma autocompreensão projetiva. O projetar-se, enquanto jogar-se em possibilidades, só é possível no horizonte de um futuro.

Mas, enquanto projeto, o Dasein permanece na maior parte das vezes num estado irresoluto, não optando pelo seu mais próprio poder-ser, permanecendo instalado no cotidiano. Assim, "a temporalidade não se temporaliza constantemente desde o futuro próprio" (HEIDEGGER, 1998, p. 353). O compreender impróprio projeta-se para as ocupações imediatas e cotidianas e faz com que o Dasein venha a si nestas ocupações, ou ainda, ele espera a si mesmo a partir do modelo das suas ocupações.

Enquanto o futuro próprio tem o caráter de 'antecipar' ou 'precursar' (Vorlaufen), o impróprio é um 'estar à espera' (Gewärtigen). No modo impróprio o Dasein espera que o futuro faça algo dele, enquanto no próprio ele se resolve e antecipa nas possibilidades e, digamos assim, faz algo de si.

Heidegger descobre o futuro temporalizado de forma imprópria, o estar à espera, como a razão pela qual a compreensão se dá a partir do impessoal. Já o futuro temporalizado de forma própria se expressa na antecipação da morte. E por isso "o precursar é um modo mais originário de estar voltado para a morte do que a preocupada espera por ela" (HEIDEGGER, 1998, p. 354).

Ele (HEIDEGGER, 1998, § 68a) nos mostra que o compreender é, no poder-ser de qualquer projeto, em primeiro lugar, um porvir. Mas está co-originariamente determinado pelo passado e pelo presente. $\mathrm{O}$ futuro impróprio tem um modo próprio de estar presente em meio aos objetos da ocupação que é a dispersão. Mas enquanto próprio, corresponde ao futuro um presente que abre a situação por meio do ato resolutório (Entschluss). Assim, pela resolução (Entschlossenheit), o presente é retirado da dispersão da ocupação imediata, e é retido no futuro e no passado. Ao presente recolhido da dispersão por meio da resolução, que é um presente próprio, Heidegger chama de 'instante' (Augenblick), e ao presente impróprio, de 'atualização' (Gegenwärtigen).

O compreender que se temporaliza a partir da atualização projeta o poder-ser a partir da decaída no 'mundo' da ocupação e, consequentemente, a partir da não-resolução. Já o instante se temporaliza a partir do futuro próprio, o que não significa que nele possa ocorrer algo, mas que ele abre o ente para um comparecimento originário. 
Já mostramos que no compreender impróprio comparece um presente que está à espera, que não se antecipa por meio da resolução. Mas deve haver, para isso, um correspondente passado. A resolução precursora produz um retorno ao si-mesmo, possibilitando assumir aquilo que ele já é. Ou como diz o próprio Heidegger, "no antecipar-se o Dasein se re-toma (Wiederholt) a si mesmo, adiantando-se em direção ao seu mais próprio poder-ser" (HEIDEGGER, 1998, p. 356). Heidegger denomina ao passado próprio de 'repetição' (Wiederholung), em oposição ao impróprio como 'esquecimento'. $\mathrm{O}$ esquecimento ignora o fato do poder-ser mais próprio e do estar jogado no mundo. E, numa expressão, Heidegger reúne os três êxtases enquanto concorrem para o compreender impróprio: "o estar à espera que esquece e atualiza é uma unidade extática peculiar, segundo a qual o compreender impróprio se temporaliza em sua temporalidade" (HEIDEGGER, 1998, p. 356). O modo impróprio dos três êxtases (abertura para o passado, presente e futuro) fecha o modo próprio do poder-ser, expressando-se existencialmente na irresolução.

\section{A temporalidade da disposição afetiva}

A disposição afetiva conduz o Dasein diante da sua condição de jogado no mundo, o que significa, um encontrar-se sempre afetado de um ou outro modo. Como diz Heidegger no parágrafo 68b, é na condição de jogado que se funda a disposição afetiva. Mas o que está em jogo aqui é o fato de que o encobrimento ou desvelamento da condição de jogado só é possível se o Dasein constantemente 'tem sido'. Por meio do êxtase do ter sido (passado), o Dasein pode encontrar-se consigo num estado afetivo. Com isso dizemos que a disposição afetiva temporaliza-se a partir do passado, assim como, por sua vez, a compreensão tem seu sentido existencial no futuro.

Mas qual a relação dos estados de ânimo com o tempo? - pergunta Heidegger (1998, p. 357). Há que se mostrar que os estados de ânimo só são possíveis sobre a base da temporalidade. Mas a análise irá limitar-se ao medo e à angústia, já anteriormente apresentados.

Como então o medo pode ser mostrado em sua temporalidade? O medo é sempre um estado de ânimo diante de um ente que de alguma forma significa uma ameaça. A ele pertence um 'estar à espera' que, enquanto tal, o caracteriza como impróprio. Assim a temporalidade do medo não é própria. 
O medo "se constitui por um esquecimento de si, pelo confuso escapar ante o próprio poder-ser fáctico em que o ameaçado ser-no-mundo se ocupa do ente à mão" (HEIDEGGER, 1998, p. 358). A ocupação como um todo se torna presa do medo e, por isso, acaba saltando de uma possibilidade para outra enquanto não assume nenhuma efetivamente como sua. $\mathrm{O}$ mundo circundante comparece sem que o Dasein possa deter-se em alguma possibilidade, e por isso atualiza (presentifica) o que primeiro aparece.

Neste estado, mesmo o 'estar à espera' acaba por tornar-se confuso, porque se temporaliza a partir do esquecimento. Dessa forma, "a temporalidade do medo é um esquecimento que, estando à espera, faz presente" (HEIDEGGER, 1998, p. 359).

E a angústia? Diferentemente do medo, o 'ante quê' da angústia é o próprio ser-no-mundo, não um ente dentro do mundo. Ela desencobre o familiar como originariamente estranho. Ela retira a possibilidade de fundar a existência a partir das coisas que nos ocupam, tornando possível um modo próprio de ser, a partir da desocultação da condição de jogado como possibilidade de repetição. Mas a angústia ainda não tem o caráter de instante, mas conduz a uma possível resolução.

Heidegger (1998, p. 361) mostra que tanto o medo como a angústia se fundam no passado, mas têm origens diferentes. $\mathrm{O}$ primeiro se origina do presente perdido, enquanto que a segunda, a partir do futuro da resolução.

Nos estados de ânimo da ocupação cotidiana se mostra sobremaneira o poder do esquecimento. Isso é constatável na indiferença, que Heidegger (1998, § 68b) caracteriza como 'descolorida indeterminação afetiva', que mostra exatamente o cotidiano abandono esquecido da condição de jogado. Essa indiferença, que pode manifestar-se inclusive numa ocupação agitada, é diferente da serenidade que, por sua vez, surge da resolução.

Qual então a relação entre a disposição afetiva e o tempo? É que somente um ente que já sempre tem sido pode ser afetado e, com isso, estar num modo de conversão (Hinkehr) ou aversão (Abkehr). E enquanto pressupõe ontologicamente a 'atualização', a afecção na atualização pode trazer o Dasein de volta a si mesmo enquanto 'sido'.

\section{A temporalidade da decaída}

Na primeira seção a consideração da decaída levou à análise do falatório, curiosidade e ambiguidade. No presente caso, será considerada somente a 
curiosidade, porque nela a temporalidade da decaída se torna mais facilmente visível (HEIDEGGER, 1998, p. 363). Como já foi mostrado, na curiosidade a compreensão não se orienta pelo fato de querer conhecer, mas simplesmente pela avidez do novo. Ela é, neste sentido, impropriamente vindoura, pois não está à espera de uma possibilidade, mas somente alimenta constantemente a avidez.

Heidegger (1998, p. 363) diz que a curiosidade tem um modo específico de presentificar que constantemente 'salta fora', pois está pouco ligada à própria coisa, visto que sua visão migra constantemente de um objeto para outro. Ela vive num constante desassossego que a alimenta e se transforma na 'falta de paradeiro', o que se opõe radicalmente ao instante, pois permite que o Dasein esteja em todos e em nenhum lugar.

Trata-se, portanto, do presente impróprio na curiosidade, que foge de um poder-ser próprio enquanto se mantém no impessoal. Nele o Dasein está numa constante espera e esquecimento. Mesmo a compreensão que o Dasein tem de si mesmo comporta-se dessa forma. A constante novidade impede que o Dasein retorne a si mesmo, mantendo-o constantemente tranquilo, tranquilização essa que garante cada vez mais a tendência de saltar fora.

Onde se funda a temporalização do 'saltar fora' própria do presente? $\mathrm{Na}$ essência finita da temporalidade, responde Heidegger (1998, p. 364). O Dasein está de início e na maior parte das vezes em fuga da condição de jogado no mundo e do estar voltado para a morte. Nesse caso "o presente salta fora de seu futuro e ter-sido próprios” (HEIDEGGER, 1998, p. 364). O Dasein precisa, então, ser levado de forma própria diante de si mesmo enquanto na condição de jogado para poder compreender-se. Mas não podemos esquecer que sua condição fática é o encobrimento e que, enquanto jogado no mundo, perde-se nele. Ou, dito de outra forma por Heidegger (1998, p. 365), a condição de estar jogado se mantém fechada quanto ao 'de onde' e ao 'como', "mas essa obstrução não é de modo algum o mero fato de não saber, senão que constitui a faticidade mesma do Dasein". E, mais adiante, diz ele que "o Dasein é arrastado pelo movimento do estar jogado; isto é, enquanto jogado no mundo se perde no 'mundo', em seu fático estar consignado àquilo de que há de se ocupar".

O presente só pode ser resgatado e trazido de volta da sua perda por meio do ato resolutório que pode "abrir, como instante retido, a respectiva situação e, junto com ela, a originária 'situação limite' de estar voltado para a morte” (HEIDEGGER, 1998, p. 365). 


\section{A temporalidade do discurso}

É o discurso articulado que constitui a abertura plena do aí (" $\mathrm{Da}$ ", no original alemão). A compreensão, a disposição afetiva e a decaída precisam do discurso para poderem ser articulados. Mas o próprio discurso não se temporaliza a partir de algum êxtase determinado, como acontece com os outros existenciais da abertura. Mas mesmo assim, diz Heidegger (1998, p. 365), pelo fato de que o discurso usa a linguagem, a fala, para se expressar e dizer as coisas com que se ocupa, a presentificação tem nele uma função constitutiva preferencial.

E como está fundado na unidade extática da temporalidade, todo discurso já é temporal em si mesmo, como mostra Heidegger (1998, p. 365). Ele nota também que os tempos verbais e os outros fenômenos verbais da linguagem estão arraigados na temporalidade originária da ocupação.

Retomando o que foi mostrado até aqui, o compreender se arraiga primariamente no futuro, adiantando-se ou estando à espera, enquanto que a disposição afetiva se funda no ter-sido (passado) na forma de repetição ou esquecimento. Já a decaída tem no presente seu enraizamento primário, na forma do instante ou da presentificação. O modo próprio dessas temporalizações está no antecipar-se, na repetição e no instante, enquanto que o impróprio está no estar à espera, esquecimento e presentificação. Heidegger (1998, p. 366), diz que

a temporalidade se temporaliza inteiramente em cada êxtase, e isso quer dizer que a unidade extática da correspondente plena temporalização da temporalidade funda a integridade do todo estrutural constituído pela existência, faticidade e decaída, isto é, a unidade da estrutura do cuidado. A temporalização não significa uma 'sucessão' dos êxtases. O futuro não é posterior ao ter-sido, nem este anterior ao presente. A temporalidade se temporaliza como futuro que está-sendo-sido e presentificante

No parágrafo 71, Heidegger põe o sentido temporal da cotidianidade novamente em questão. Ela, a cotidianidade, é o modo em que o Dasein é de início e na maior parte das vezes, o modo no qual ele se mantém 'todos os dias' durante a sua vida. É, portanto, um 'como' da existência, uma maneira de ser que se caracteriza pela abertura pública, mas da qual a existência tem a possibilidade de apropriar-se por meio do instante, mas sem nunca se transpor para fora dela.

Rev. Filos., Aurora, Curitiba, v. 22, n. 30, p. 247-266, jan./jun. 2010 
E Heidegger (1998, p. 386-387) pergunta-se sobre a suficiência ou não da explicação precedente sobre a temporalidade para esclarecer esse fenômeno. Conclui que ainda será necessário conseguir uma suficiente elaboração da questão do sentido do ser em geral para poder alcançar suficientemente a cotidianidade por meio de uma determinação conceptual.

Mas lembra que todos os esforços na elaboração da analítica existencial têm como finalidade abrir espaço para responder a questão do sentido do ser em geral. Isso só é possível abordando o fenômeno no qual se torna acessível a questão do ser, ou seja, na compreensão. E, compreensão é um fenômeno que pertence à constituição do Dasein. Dessa forma, o primeiro passo significa um esclarecimento desse ente para poder avançar para a questão do sentido do ser em geral.

\section{Considerações finais}

O texto se propôs investigar brevemente a descrição do modo de ser do existir humano feita por Martin Heidegger na sua obra Ser e Tempo, publicada em 1927. O foco da análise foi a apresentação do modo primeiro e geral em que o ser humano, aqui chamado Dasein, se apresenta e que nosso autor chama de cotidianidade, e, em sequência, apresentar a reflexão realizada em torno da possibilidade de apropriar-se de si mesmo, do poder-ser próprio. Procuramos evidenciar um dos fios condutores dessa obra, ou seja, a descrição do Dasein partindo da cotidianidade, passando para a possibilidade do poder-ser próprio na resolução. Com isso torna-se visível a consideração do fato fundamental do Dasein ser essencialmente ser-no-mundo e que esse fato mantém-se oculto na cotidianidade e é retomado na medida em que, a partir da temporalidade, ele redescobre o seu ser originário. Procuramos acompanhar Heidegger, embora de forma limitada e despretensiosa, na aproximação da historicidade, da temporalidade. A partir desta, o saber histórico desliga-se da presentificação, do decaído caráter público do tempo, e adquire o caráter de abertura resoluta.

A analítica existencial realizada em Ser e Tempo procurou fazer a desconstrução e liberação do Dasein para o seu próprio modo de ser. Por meio de uma hermenêutica do Dasein, esclarece como ele se compreende no mundo, em primeiro lugar, a partir dos entes com que lida e, em segundo lugar, a partir do impessoal e das possibilidades herdadas. Com isso, Heidegger procura liberar o Dasein no seu ser próprio enquanto cuidado, e este, por sua 
vez, recebendo seu sentido a partir da temporalidade, deve poder alcançar um espaço originário para a questão do sentido do ser em geral.

A linguagem empregada nos textos, inclusive em Ser e Tempo, apresenta enormes dificuldades, mesmo para quem já está um pouco familiarizado com o pensamento do autor. Por isso, procuraremos retomar as ideias desenvolvidas considerando a reflexão realizada por alguns comentadores, no que se refere à passagem do tempo para a temporalidade. É preciso, de certa forma, transportar-se para fora do universo de objetos, de objetificação, e situar-se no horizonte da fenomenologia hermenêutica, um âmbito em que se exercita a libertação da linguagem da sua carga de conteúdos pré-estabelecidos e da sua determinação objetificadora. Heidegger, a partir das conquistas dos pensadores que o precederam e de seus contemporâneos, solidifica um novo 'paradigma' que busca quebrar as amarras da tradição, não no sentido de condenar o passado, mas de encontrar o próprio ser de possibilidades, o pensamento contra o cálculo.

Uma nova visão de ser humano emerge desse trabalho. O ser do ser humano não pode ser compreendido pela comparação com o ser das outras coisas no mundo. As ciências humanas estão diante do desafio de conhecer o ser humano sem tornar-se presa da ontologia da coisa, de enfrentar e diferenciar a temporalidade da coisa da temporalidade do ser humano. Stein (2008, p. 33) diz que

[...] no universo da liberdade humana, da História, da ação, da vontade, na maneira de o homem ser no mundo existe uma idéia de lugar, de espaço, de tempo, que nada tem a ver com a temporalidade da coisa. Assim, nunca chegamos à temporalidade humana por meio da temporalidade dos objetos. Não há como partir da física para estabelecer a temporalidade da existência humana.

A subjetividade não pode ser simplesmente reduzida à coisa, medida pela 'medida' dos objetos que não tem o modo de ser do ser humano. A inteligibilidade do que seja o ser humano exige uma nova postura, que o reconheça como ser-no-mundo, já sempre compreendendo o ser, na abertura do ser. O tempo das coisas, medição, sucessão de momentos indiferentes não corresponde à temporalidade do ser humano. $\mathrm{O}$ universo do sentido soa de outra forma. A crítica à metafísica é uma crítica à compreensão tradicional do tempo. Heidegger procura mostrar, por meio da análise da temporalidade da compreensão, da disposição afetiva, da decaída e do discurso, uma forma 
nova de encarar o ser humano, sua relação com a linguagem, com as coisas e com os outros seres humanos. Se, num primeiro momento, apresenta as consequências da consideração do tempo enquanto presença, presentificação, mais tarde esclarece a possibilidade da superação em direção à propriedade, da compreensão autêntica e própria.

A marca fundamental desse pensamento é a finitude. Essa característica do ser humano foi omitida, esquecida, escondida pela atenção ao modo de ser dos objetos. Olhando para o ser humano pelas lentes ajustadas para os objetos não humanos, perde-se a especificidade deste ente, ou seja, sua finitude. Não há, para ele, transparência total, imparcialidade, que são ideais da ontologia da coisa. Isso porque o ser humano, em todas as suas realizações, existe "no espaço e no tempo, limitado, dotado de características temporais e caráter histórico. Ele é historicidade" (STEIN, 2008, p. 80). Quem sustenta todo conhecimento e ação é o próprio ser humano, finito, ser-para-a-morte. A propriedade, diferentemente da ontologia da coisa, aproxima o ser humano, agora Dasein, da sua condição indepassável, da sua finitude radical, do seu irremediável ser-para-a-morte.

Ao propor a revisão da tradição e realizar sua crítica às ontologias tradicionais a partir do conceito de tempo, Heidegger revoluciona na filosofia, transformando essencialmente o conceito de ser. No seu pensamento, "não era apenas o caráter físico da sucessão do tempo que era suplantado, mas se produzira uma desobjetificação do ser humano, na medida em que cada existencial é uma concentração de instantes de temporalidade" (STEIN, 2004, p. 293). Nessa desobjetificação do ser humano, os conceitos tradicionais, carregados de conteúdos e vícios, precisam ser substituídos por aquilo que Heidegger chama de 'existenciais', indícios que apontam para o próprio acontecer do ente humano. E, ainda, como mostra Stein (2004, p. 295), comentando a superação do tempo como sucessividade física atomicamente recortada, que

Heidegger não apenas rompe a sucessividade do tempo do mundo, mas a inverte de tal modo que sem o ser humano nada pode ser considerado como se dando no tempo. Essa inversão não tem como conseqüência a redução da importância de tudo o que se dá no mundo físico, mas pelo contrário, insere o cosmos na própria dramaturgia da existência.

A linearidade do tempo é substituída pela dimensão ec-stática, pela abertura de sentido na qual se apresenta o todo da condição humana, 
onde acontece o "refluxo do futuro e do passado sobre o momento presente" (STEIN, 2004, p. 293). Uma das ideias fundamentais aqui é a da abertura: ela somente existe se não se está preso à presença, ao presente. Somente há transcendência onde não se está capturado pela imanência do presente. O tempo da sucessão de momentos, da presencialidade, somente pode 'ver', fazer sentido, se não estiver preso em si mesmo. O tempo presente, por assim dizer, está capturado em si mesmo, é cego e surdo se não tiver, no próprio presente, a presença do passado e do futuro. Essa dimensão ec-stática é que abre a possibilidade de pensar o tempo e permite que aconteçam objetos e eventos no tempo. E a abertura que se realiza pela presença do passado por meio da memória e do futuro pelo projeto somente acontece num ente determinado chamado Dasein. É nele e através dele que há algo, que há sentido, significado. O tempo somente 'vê' se há a temporalidade. Sem a temporalidade do Dasein, há cegueira e surdez, não há algo, nem tempo.

O tempo pensado a partir do presente não alcança sua dimensão originária enquanto tempo humano. As coisas se manifestam, aparecem no presente, mas elas não seriam o que são, delas não se diria que são, ou não se diria que há algo, se não houvesse a transcendência possível por causa da elasticidade, da distensão para frente e para trás, para o passado e para o futuro. Somente pela transcendência há algo, ou seja, pela temporalidade do Dasein. Assim o tempo adquire uma importância e um peso crucial para a questão do ser, tema central do pensamento heideggeriano. O ser tem uma relação íntima com o tempo. O sentido do ser somente se revela a partir do Dasein e, sendo o Dasein temporal, histórico, finito, tudo o que ele pensa, diz e conhece é também temporal, histórico, finito.

A temporalidade, a historicidade, permite a autenticidade do Dasein, pelo fato de que ele não é "totalmente absorvido pelo presente nem pelo passado e pelo futuro imediatos" (INWOOD, 2004, p. 83). Diferentemente, o Dasein autêntico "olha prospectivamente para sua morte e retrospectivamente para o seu nascimento e, indo além de seu nascimento, para o passado histórico" (INWOOD, 2004, p. 84). O presente não é independente do passado e nem do futuro. Diz o mesmo autor que o

Dasein não se restringe em sua consciência ao momento presente. Ele se projeta no futuro e retrocede ao passado. O Dasein é temporal. É a temporalidade do Dasein que torna o mundo genuinamente temporal, que abre o 'tempo-do-mundo' e desvela um mundo que perdura (INWOOD, 2004, p. 85). 
Não há nessa compreensão de tempo nenhuma rejeição da concepção de tempo que permite as ciências dos objetos. Mas há aqui a indicação de que as coisas só têm significado a partir do momento em que há Dasein, há seres humanos. Somente quando há Dasein, "começaram a história, a significância, a mundanidade e, de certo modo, o próprio tempo" (INWOOD, 2004, p. 85). Trata-se, quando se fala de temporalidade do Dasein, do tempo originário, do horizonte de abertura temporal prévio que permite a posterior lida com o tempo das coisas, do movimento. Sandbothe (2003, p. 88) diz que "[...] o tempo não é somente a condição teórica da possibilidade para que possamos fixar algo como algo no 'agora', mas a condição existencial para que se possa projetar um mundo em geral $[\ldots]$ ”.

Esse tempo originário é finito, termina com a minha morte. Quando o Dasein reconhece a sua finitude, introduz na sua vida a perspectiva da morte e, com isso, elimina o perpétuo adiamento das decisões. Enquanto a finitude é mantida no esquecimento, ocultada pela postura cotidiana de apego aos objetos que se dão na abertura do mundo, característica própria da metafísica tradicional, o ser humano vive como se fosse eterno, dominado pelo impessoal, livre da responsabilidade pelas decisões que fazem algo com a vida. A responsabilidade pelo próprio destino, pelo próprio ser, é retomado com a consciência da morte, da finitude. Inwood (2004, p. 91) diz que "a maneira como organizo minha vida sem dúvida depende de minha certeza quanto ao fato de que vou morrer em algum momento e de minha incerteza com relação a quando vou morrer".

Com a morte, com o fim do tempo, acaba-se o ser de possibilidades do Dasein. Na morte ele é aquilo que fez de si mesmo, por meio das suas decisões, omissões ou das decisões impessoais que ele permitiu que dirigissem sua vida. A 'minha' morte individualiza, separa do impessoal, é o momento mais pessoal, em que somente eu participo, em que sou isolado do envolvimento da multidão e da correspondente não responsabilidade pelas decisões na vida. Na resolução, que se torna possível quando se descobre a finitude, o Dasein "unifica a si mesmo ao mesmo tempo em que se abre" (INWOOD, 2004, p. 101) e ao separar-se do imperativo da multidão pode tomar as decisões à luz da sua vida como um todo. Ao passar do tempo à temporalidade adquirese uma competência que evita que se seja dominado pelas determinações da tradição, pelo envolvimento com os objetos que se dão na abertura. A própria abertura se 'mostra' e domina-se a tradição ao invés de ser por ela dominado.

Mas o que seria efetivamente a propriedade, a condição própria do ser humano? Pöggeler (2001, p. 226) alerta que "o próprio não é aquilo que é 
buscado numa fuga romântica para o passado ou na imaginação de um futuro ilusório e afirmado obstinadamente contra a realidade". A propriedade não é nenhum estado paradisíaco, fora do mundo, mas também não pode ser descrito ao modo dos objetos. Não é uma realidade objetiva, nenhum modelo prévio ou ideal coletivo. Mas é a experiência da verdade e do mundo. Da verdade como a abertura do ser. É a lembrança do esquecimento que esqueceu seu solo próprio, originário, fático, ser-no-mundo finito. É, como diz o mesmo autor, "aquilo que, como o esquecido e o dissimulado, suporta o 'real'. Por isso é que ele só pode ser achado por meio de um 'olhar para dentro de aquilo que é", (PÖGGELER, 2001, p. 226). A fenomenologia hermenêutica busca resgatar 'aquilo que é', por meio de uma desconstrução da tradição metafísica, de uma libertação para a faticidade, a originariedade.

Como buscamos mostrar, a compreensão, a disposição afetiva, a decaída e o discurso podem ser vistos da perspectiva da ontologia da coisa, do tempo, tal como acontece na metafísica, na tradição. Mantém-se, assim, na impropriedade e inautenticidade. A partir da temporalidade, da ontologia fundamental, do Dasein, é que se conquista o horizonte prévio e originário onde as coisas e o tempo adquirem significado, entram no âmbito do sentido.

\section{Referências}

GRONDIN, J. Die Wiedererweckung der Seinsfrage auf der Weg einer phänomenologischhermeneutischen Destruktion. In: RENTCH, T. (Hg.). Martin Heidegger, Sein und Zeit. Berlin: Akademie Verlag GmbH, 2007. p. 1-27.

HAAR, M. Heidegger e a essência do homem. Tradução de Ana Cristina Alves. Lisboa: Instituto Piaget, 1990.

HEIDEGGER, M. Ser y tiempo. 2. ed. Tradução Jorge Eduardo Rivera. Santiago de Chile: Editorial Universitaria, 1998.

INWOOD, M. Heidegger. São Paulo: Loyola, 2004.

PÖGGELER, O. A via do pensamento de Martin Heidegger. Lisboa: Instituto Piaget, 2001.

SANDBOTHE, M. Zeit: von der Grundverfassung des Daseins zur Vielfalt der ZeitSprachspiele. In: DIETER, T. (Hg.). Heidegger Handbuch. Weimar: Verlag J. B. Metzler, 2003. p. 87-92. 
STEIN, E. Exercícios de fenomenologia: limites de um paradigma. Ijuí: UNIJUÍ, 2004.

Racionalidade e existência: o ambiente hermenêutico e as ciências humanas. 2. ed. Ijuí: UNIJUÍ, 2008.

Recebido: 20/09/2009

Received: 09/20/2009

Aprovado: $17 / 04 / 2010$

Approved: 04/17/2010 